\title{
Indoor Air Quality Evaluation of Commercial Buildings In Kuantan
}

\author{
Noor Huwaida Yahaya ${ }^{1}$, Ftwi Yohaness Hagos $^{1,2}{ }^{*}$, Mohamad Firdaus Basrawi ${ }^{3}$ \\ ${ }^{1}$ Advance Fluids Focus Group, Faculty of Mechanical Engineering, Universiti Malaysia Pahang, \\ 26600 Pekan, Pahang, Malaysia. \\ ${ }^{2}$ Automotive Engineering Centre, Universiti Malaysia Pahang, 26600 Pekan, Pahang, Malaysia. \\ ${ }^{3}$ Energy Sustainability Focus Group, Faculty of Mechanical Engineering, Universiti Malaysia Pahang, \\ 26600 Pekan, Pahang, Malaysia
}

\begin{abstract}
This work focuses on indoor air quality evaluation of commercial buildings in Kuantan. Some buildings have been selected to monitor indoor air quality. The research has been carried out only in Kuantan, which focused on hotels and government buildings. Some sample measurements were taken which include air temperature, relative humidity, and air movement, carbon monoxide $(\mathrm{CO})$, carbon dioxide $(\mathrm{CO} 2)$, ozone $(\mathrm{O} 3)$, respirable particulate matter (PM 10), formaldehyde and total volatile organic compound (TVOC). In addition, questionnaires were conducted on a number of workers in each building to determine the level of health and illness caused by air in the building where they work. Hence, this study has analyzed the link between the questioner results and the results of indoor air measurements that were carried out. From surveys, it appears there are four buildings that have low air flow, four buildings have a lot of dust and five buildings have a high temperature. In contrast, four buildings have a good indoor air quality.
\end{abstract}

\section{Introduction}

Indoor air quality (IAQ) is a term which refers to the air quality within and around buildings and structures, especially as it relates to the health and comfort of building occupants [1]. IAQ can be affected by gases (including carbon monoxide, radon, volatile organic compounds), particulates, microbial contaminants (mold, bacteria), or any mass or energy stressor that can induce adverse health conditions. Source control, filtration and the use of ventilation to dilute contaminants are the primary methods for improving indoor air quality in most buildings [2-5]. Residential units can further improve indoor air quality by routine cleaning of carpets and area rugs.

Determination of IAQ involves the collection of air samples, monitoring human exposure to pollutants, collection of samples on building surfaces, and computer modeling of air flow inside buildings. IAQ is part of indoor environmental quality (IEQ), which includes IAQ as well as other physical and psychological aspects of life indoors (e.g., lighting, visual quality, acoustics, and thermal comfort). Indoor Air Quality (IAQ) is common term used to describe

*Corresponding author: ftwi@ump.edu.my 
the quality of air within a building environment. It is of great concern to governmental, region and worldwide influential organizations because of its impact on human health. In indoor environments, human exposure to air pollutants can have negative effects on the well-being of occupants [6]. Even overlooked factors, if left unchecked, could weaken IAQ. Therefore, many countries national organizations and worldwide influences committees for instance the World Health Organization (WHO) has stipulated standard and guidelines are implemented with the general consensus of limiting exposure of humans to certain breathing air contaminants.

The frequent air pollutants contributing to weaken IAQ are carbon monoxide (CO), carbon dioxide $\left(\mathrm{CO}_{2}\right)$, formaldehyde $(\mathrm{HCHO})$, nitrogen dioxide $\left(\mathrm{NO}_{2}\right)$, sulfur dioxide $\left(\mathrm{SO}_{2}\right)$, and total volatile organic compounds (TVOC). Air temperature, velocity, and humidity levels are further IAQ factors associated with thermal comfort zone. The eventual disposition of the indoor environment as a result of ignoring guidelines and standards may cause sick building syndrome (SBS) [7]. SBS term is used to describe environments with the poor air quality. The adverse side effects on human health might be headaches, nausea, drowsiness and shortness of breath.

Indoor air pollution in developing nations is a major health hazard. A major source of indoor air pollution in developing countries is the burning of biomass (e.g. wood, charcoal, dung, or crop residue) for heating and cooking. The resulting exposure to high levels of particulate matter resulted in between 1.5 million and 2 million deaths in 2000 [8].

Indoor air quality should be emphasized in any society, particularly in the health and comfort of performing daily activities. Indoor air quality problems are detected and can be serious and would be harmful to human health if not monitored. Air quality can be monitored based on complaints from residents about health problems and signs of illness [2,3,9]. The purpose of this monitoring is to identify the level of indoor air quality. The parameters measured were carbon dioxide, carbon monoxide, respirable particles, TVOC, formaldehyde, ozone and physical parameters such as temperature, relative humidity and air movement. In addition, the volumetric flow rate of outside air per occupant and the air exchange rate per hour is also determined [10-12]. A total of ten commercial buildings in Kuantan which have been identified to conduct indoor air quality monitoring and comparing them with Industrial Code of Practice (ICOP).

Indoor Air Quality monitoring are done according to Industry Code of Practice (ICOP) in indoor air quality (IAQ) 2010 which developed by Department of Occupational Safety and Health Malaysia. It is used as major reference in the preliminary IAQ assessment. ICOP provide minimum standard for selected indoor parameters and provide guidance to improve IAQ and avoid discomfort or adverse health affect among building occupants in enclosed environment which were equipped with mechanical ventilation and air conditioning (MVAC) system. The acceptable range or exposure limits of physical parameter, chemical and biological contaminants in this ICOP were used as reference.

The general objective is to determine the level of Indoor Air Quality in workplaces. The specific objectives includes, to do Indoor Air Quality Monitoring and comparing the results with Industry Code of Practice (ICOP) in indoor air quality (IAQ) 2010; to determine potential sources of indoor air contaminant; to determine the level of indoor air contaminants which are: Air temperature, relative humidity, and air movement, carbon monoxide (CO), carbon dioxide $\left(\mathrm{CO}_{2}\right)$, ozone $\left(\mathrm{O}_{3}\right)$, respirable particulate matter (PM 10), formaldehyde, total volatile organic compound (TVOC). Another objective is to conduct surveys on health effect of occupants of each building by using questionnaires. Also the relationship between these two objectives. 


\section{Experimental Setup}

In order to collect samples of the measurements, there are some factors that need to be considerate such as sample positions, sampling period and sampling techniques which will be discussed details in this section. During field data collection, monitors should be positioned at the selected sampling location using the criteria from general guidelines such as: representing the primary workstation layout and work activities; the position should be of minimal disturbance of work activities within the study area; at least $0.5 \mathrm{~m}$ from corners or windows, walls, partitions, and other vertical surfaces; not directly in front of air supply diffusers, induction units, floor fans, or heaters, or the exhaled breath of the operator; not under direct sunlight that will impact instrumentation; preferably not in hallways or passageways; at least 1 meter from localized sources such as photocopiers, printers; not within $3 \mathrm{~m}$ of an elevator if sampled at a corridor / lobby; not within $2 \mathrm{~m}$ of doors; not obstructive to, or interfering with, occupant egresses from the study area under normal or emergency situations; not at the junction connected to stations of the public transport facilities; placing inlets of samplers at a height between 75 and $120 \mathrm{~cm}$, preferably $110 \mathrm{~cm}$ from the floor [13-15].

\subsection{Sampling Period and Techniques}

Measurement of IAQ parameters should be made on an 8-hour basis except otherwise specified. Where it is not practical to take 8-hour continuous measurement, surrogate measurement (i.e. an intermittent measurement strategy based on the average of half an hour measurement conducted at four time-slots) is also accepted [4]. The operation pattern of the buildings should be taken into account when choosing the four time-slots.

The four time-slots should be evenly distributed over the business hours for office buildings whereas for public places they should cover the worst case scenario such as periods of highest occupancy. If real-time monitor is used, at least one reading should be taken every 5 minutes at each sampling point either with a data logging device or by properly recorded in a field data $\log$ sheet, regardless of whether the 8-hour continuous or surrogate measurement strategy is adopted [16,17].

All measurements should be conducted using calibrated instrument/equipment and the calibration should be conducted according to manufacturer's specifications where available.

There are basically two types of assessment methods, namely real-time measurements and integrated sampling with subsequent laboratory analysis.

Real-time monitors can be used for detection of contaminant sources and provide information on the variation of contaminant levels throughout the day. Integrated samples, normally obtained during the 8 working-hours for offices, can provide information on the total exposure level of a particular contaminant. Samples were taken by using the tool IAQ for 30 minutes. Count 8-hour exposure limit formula is as follows;

$$
X T W A=\frac{C_{1} T_{1}+C_{2} T_{2}+\cdots C_{n} T_{n}}{T_{1}+T_{2}+\cdots T_{n}}
$$

whereas XTWA is integrated sampling, $\mathrm{C}$ is chemical concentrations (in $\mathrm{ppm}, \mathrm{mg} / \mathrm{m} 3$ at $25^{\circ} \mathrm{C}$ ) and $\mathrm{T}$ is monitoring period (in minutes). The measurement is carried out substitute measuring the intermittent measurement strategy based on an average of half an hour measurements performed at 4 time slots. The method of measurement used is the measurement of real-time (real-time measurement) of physical parameters and chemical contaminants. $\mathrm{C}$ is the ceiling limit that shall not be exceeded at any time. Readings above $1000 \mathrm{ppm}$ are indication of inadequate ventilation. These calculations apply only to the carbon 
monoxide, TVOC, respirable particles, formaldehyde and ozone. Parameters for $\mathrm{CO} 2$, readings refers to the maximum ceiling limit. As for the temperature, velocity and $\mathrm{RH} \%$ is average. The measurement taken at the buildings are then compared with ICOP standards as shown in Table 1, 2 and 3.

Table 1. Acceptable range for specific physical parameters.

\begin{tabular}{|l|l|}
\hline Parameter & Acceptable range \\
\hline Temperature & $23-26^{\circ} \mathrm{C}$ \\
\hline Relative Humidity & $40-70 \%$ \\
\hline Air movement & $0.15-0.50 \mathrm{~m} / \mathrm{s}$ \\
\hline
\end{tabular}

Table 2. List of indoor air contaminants and the acceptable limits.

\begin{tabular}{|l|l|}
\hline Chemical Contaminants & Acceptable limit \\
\hline Carbon monoxide & $10 \mathrm{ppm}$ \\
\hline Formaldehyde & $0.1 \mathrm{ppm}$ \\
\hline Ozone & $0.05 \mathrm{ppm}$ \\
\hline Respirable particulate & $0.15 \mathrm{mg} / \mathrm{m}^{3}$ \\
\hline $\begin{array}{l}\text { Total volatile organic } \\
\text { compounds (TVOC) }\end{array}$ & $3 \mathrm{ppm}$ \\
\hline
\end{tabular}

Table 3. Ventilation Performance Indicator and the acceptable limit.

\begin{tabular}{|l|l|}
\hline $\begin{array}{l}\text { Ventilation Performance } \\
\text { Indicator }\end{array}$ & Acceptable limit \\
\hline Carbon dioxide & $\mathrm{C} 1000$ \\
\hline
\end{tabular}

For the collection of data, there are six equipment used to collect each samples which are TVOC meter ppbRae 3000, DustTrak monitor 8520, air quality monitor Quest AQ5000, anemometer TSI Velocicalc 9555, PPM Formaldemeter htV-m, Ozone Meter Aeroqual 500. Summary of the equipment used in the data collection are presented in Table 4.

\subsection{Data Collection and Information}

Data and information about health effects are obtained from building occupant through conducting questionnaires to residents in the workspace. The questionnaires include workplace environment conditions which are draught, room temperature too high, varying room temperature, room temperature too low, stuffy "bad" air, dry air, unpleasant odor, static electricity, passive smoking, noise, light that is dim, and also dust dirt. Besides, the questionnaires also include disease symptoms that might affect respondents of each Building. The disease symptoms include fatigue, headache, dizziness, nausea, difficulties, itching of the eyes, stuffy or runny nose, dry throat, cough, dry facial skin skin, and itching scalp. 
Table 4. List of Equipment.

\begin{tabular}{|l|l|l|}
\hline \multicolumn{1}{|c|}{ Category } & \multicolumn{1}{|c|}{ Properties } & \multicolumn{1}{|c|}{ Equipment } \\
\hline Physical Parameter & Air movement & Velocity meter \\
\cline { 2 - 3 } & Temperature & $\begin{array}{l}\text { Air } \\
\text { Monitor }\end{array}$ \\
\cline { 2 - 3 } & $\begin{array}{l}\text { Relative } \\
\text { humidity }\end{array}$ & $\begin{array}{l}\text { Air } \\
\text { Monitor Quality }\end{array}$ \\
\hline $\begin{array}{l}\text { Chemical } \\
\text { Contaminants }\end{array}$ & $\begin{array}{l}\text { Respirable } \\
\text { Particulate } \\
\text { PM }\end{array}$ & $\begin{array}{l}\text { Dust Trak Aerosol } \\
\text { Multimeter }\end{array}$ \\
\cline { 2 - 3 } & TVOC & TVOC meter \\
\cline { 2 - 3 } & CO & $\begin{array}{l}\text { Air } \\
\text { Monitor }\end{array}$ \\
\cline { 2 - 3 } & Ozone & Ozone meter \\
\cline { 2 - 3 } & Formaldehyde & Formaldemeter \\
\hline $\begin{array}{l}\text { Ventilation } \\
\text { Performance } \\
\text { Indicator }\end{array}$ & CO2 & $\begin{array}{l}\text { Air } \\
\text { Monitor }\end{array}$ \\
\hline
\end{tabular}

\section{Results and Discussion}

\subsection{Air Movement}

Based on Figure 1, it has been shown that the measurements taken for air movements is very low for buildings 1, 2, 3 and 5. Among the potential causes of the problem areas is because there are no air movement (air off). Very low air movement can caused discomfort to the occupants such as difficulties in breathing. Air movement in air-conditioned spaces would make occupants feel cooler because of greater heat loss from the human body. However, air movement that is too high might cause draft and undesired local discomfort [16].

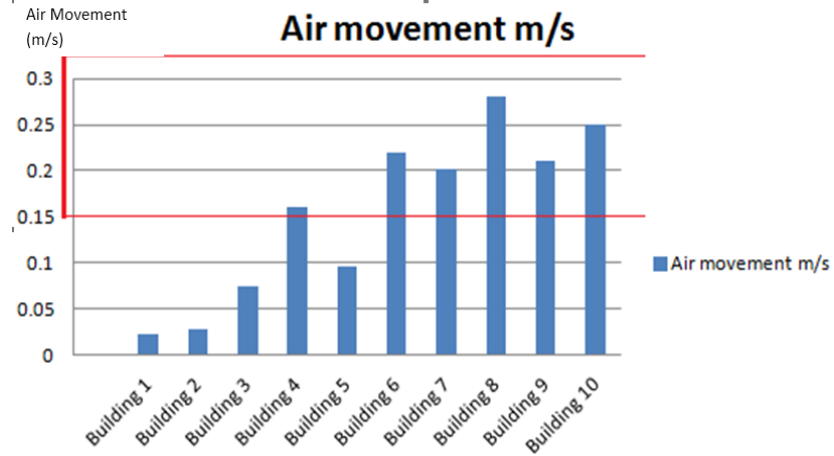

Fig. 1. Air movement in different buildings and ICOP standards limit.

In order to overcome this problem, building owner have to ensure that there are not too many people occupied the building also ensure that HVAC systems are all well maintained and in a good condition. 


\subsection{Carbon monoxide}

It is been shown that the $\mathrm{CO}$ measurements taken for all buildings are between the acceptable ranges as shown in Figure 2. However, if the $\mathrm{CO}$ measurements are out of acceptable range, there might be some effect to building occupants. Breathing $\mathrm{CO}$ can cause headache, dizziness, vomiting, and nausea. If $\mathrm{CO}$ levels are high enough, you may become unconscious or die. Exposure to moderate and high levels of $\mathrm{CO}$ over long periods of time has also been linked with increased risk of heart disease.

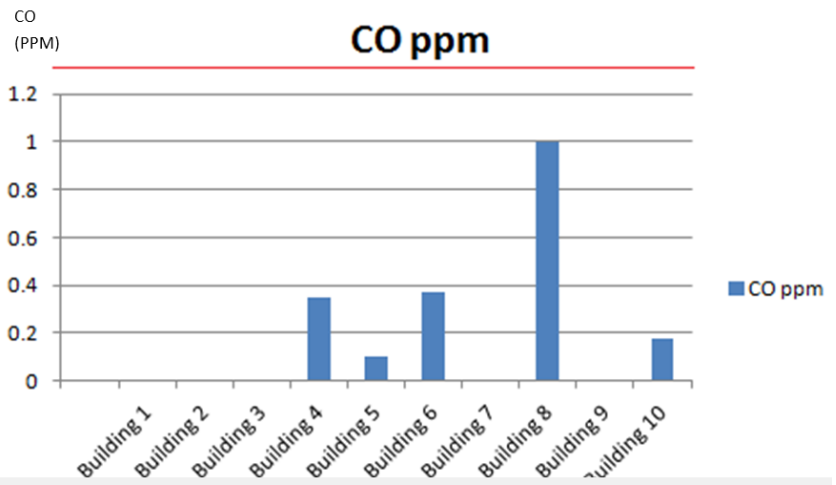

Fig. 2. CO measurement of different buildings and its corresponding ICOP standards limit.

\subsection{Carbon dioxide}

Figure 3 shows the carbon dioxide measurement of different buildings in parts per million (ppm). It has been shown that measurements taken for all buildings are between the acceptable ranges. However, if the $\mathrm{CO}_{2}$ measurements are out of acceptable range, there might be some effect to building occupants. Very high concentrations of atmospheric $\mathrm{CO}_{2}$ can produce a state of hypercapnia or an excessive amount of $\mathrm{CO}_{2}$ in the blood [15,17], which typically results in acidosis, a serious and sometimes fatal condition characterized in humans by headache, nausea and visual disturbances [11].

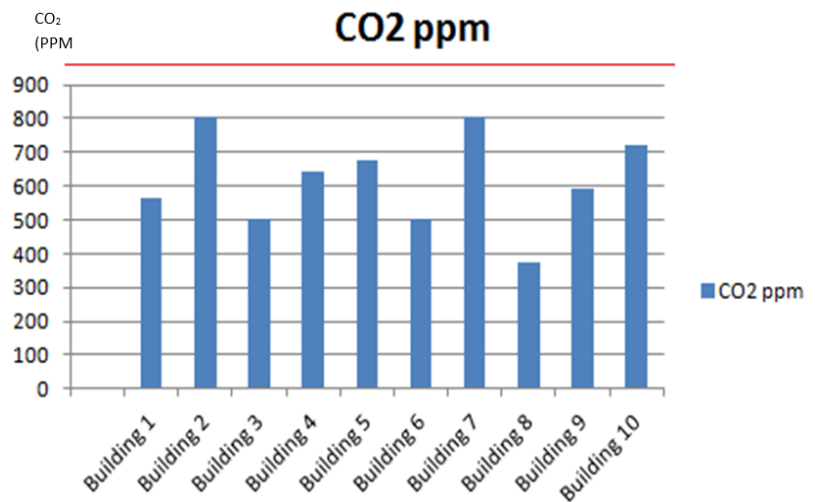

Fig. 3. $\mathrm{CO} 2$ measurement of different buildings and its corresponding ICOP standards limit.

However, these phenomena do not impact human health until the atmosphere's $\mathrm{CO}_{2}$ concentration reaches approximately $15,000 \mathrm{ppm}$ [11], which is approximately 40 times greater than its current concentration. Hence, we do not have to worry about any direct negative health effects of the ongoing rise in the air's $\mathrm{CO}_{2}$ content. 


\subsection{TVOC}

The TVOC measurement of the buildings under investigation is presented in Figure 4. It has been shown that measurements taken for all buildings are between the acceptable ranges. However, if the TVOC measurements are out of acceptable range, there might be some effect to building occupants. Health effects include eye, nose, and throat irritation; headaches, loss of coordination, nausea; and damage to the liver, kidney, and central nervous system. Some organics can cause cancer in animals; some are suspected or known to cause cancer in humans. In order to reduce exposure to TVOC, do not store opened containers of unused paints and similar materials and use integrated pest management techniques to reduce the need for pesticides.

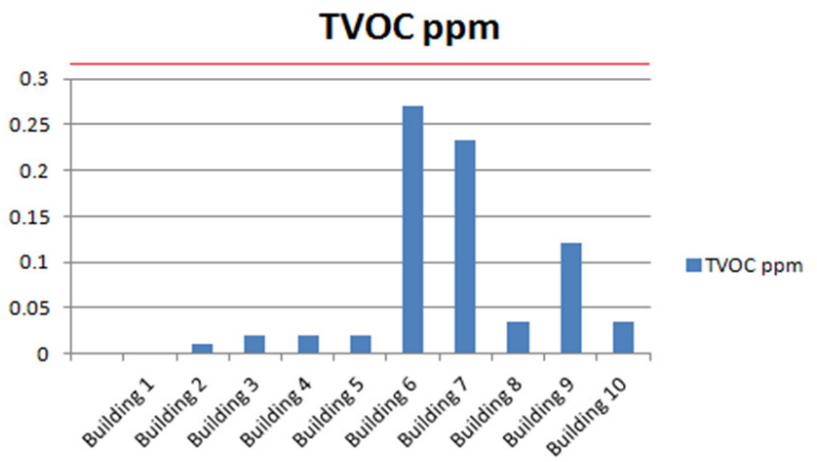

Fig. 4. TVOC measurement of different buildings and its corresponding ICOP standards limit.

\subsection{Respirable Particulate}

\section{Respirable Particulate $\mathrm{mg} / \mathrm{m} 3$}

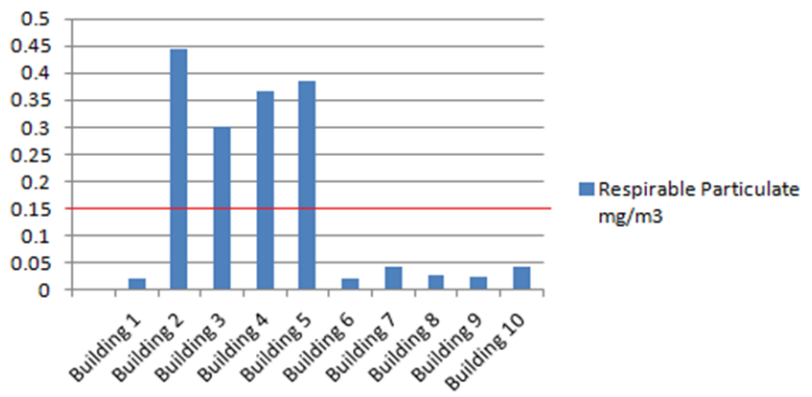

Fig. 5. . Respirable particulate $(\mathrm{mg} / \mathrm{m} 3)$ measurement of different buildings and its corresponding ICOP standards limit.

Based on Figure 5, it has been shown that for Buildings 2, 3, 4 and 5, the measurements taken for respirable particulate (dust) are quite high. The potential problems might be due to collected dust from textures surfaces such as carpeting and curtains. There are also lots of dusts because of the buildings age that are more than 20 years. In order to overcome this problem, the buildings condition needs to be well maintained by maintaining the cleanliness of floors and furniture inside the building. 


\subsection{Ozone}

The Ozone measurement of the buildings under study is presented in Figure 6. It has been shown that measurements taken for all buildings are between the acceptable ranges. However, if the ozone measurements are out of acceptable range, there might be some effect to building occupants. Studies have shown that short-term exposure to peak levels of ozone can temporarily affect the lungs, the respiratory tract, and the eyes, and can also increase susceptibility to inhaled allergens. Long term exposure to ozone has primarily been found to reduce lung function.

\section{Ozone ppm}

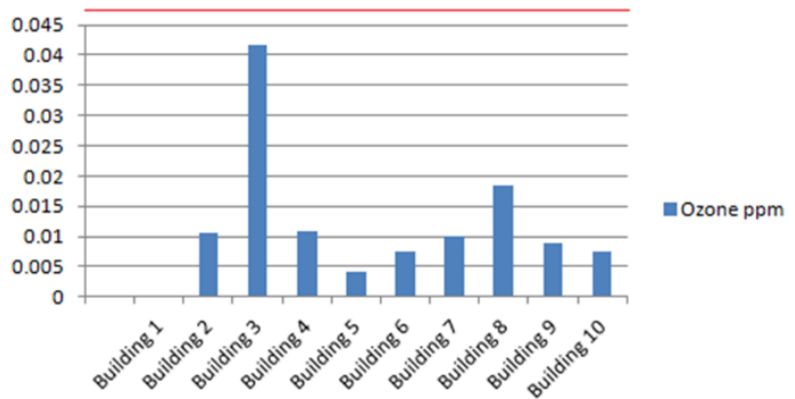

Fig. 6. . Ozone measurement of different buildings and its corresponding ICOP standards limit.

\subsection{Temperature}

Based on Figure 7, it has been shown that for Buildings 2, 3, 4 5, and 6, the temperature are quite high. The potential problems also might be due to the buildings age that are more than 20 years, therefore some of the air conditionings system might not work properly. High temperature can cause discomfort to building occupants such as headache, dizziness and fatigue. Very hot environments can overwhelm the body's coping mechanisms leading to a variety of serious and possibly fatal conditions. In order to prevent high temperature, air conditioning system in the building needs to be maintained properly according to schedule.

\section{Temp. ${ }^{\circ} \mathrm{C}$}

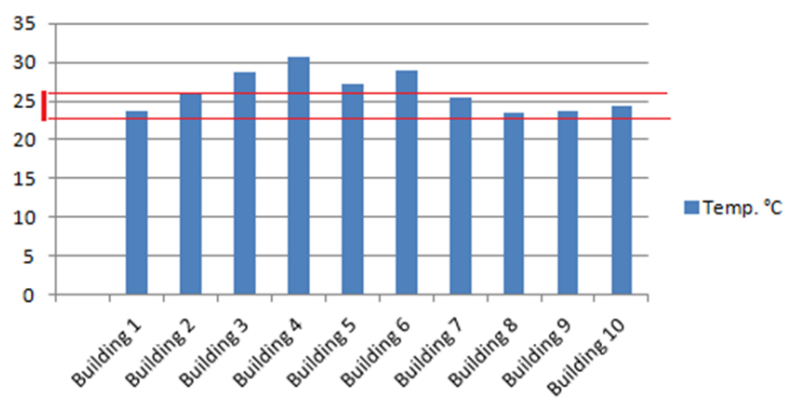

Fig. 7. Temperature measurement of different buildings and its corresponding ICOP standards limit.

\subsection{Relative humidity}

Based on Figure 8, it has been shown that measurements taken for all buildings are between the acceptable ranges. However, if the RH measurements are out of acceptable range, there might be some effect to building occupants. Condensation forms when air with a high relative humidity $(\mathrm{RH})$ comes in contact with surfaces that are below the dew-point temperature. Whether it be interior window sills or hidden structural assemblies, once wood absorbs $30 \%$ 
of its weight in water it can begin to rot. The most effective approach to reducing airtransported moisture is to seal the building tightly against air infiltration or exfiltration. This keeps damp outside air outside and allows the building's ventilation and air-conditioning system to remove excess moisture from the air inside the building.

\section{Relative humidity \%}

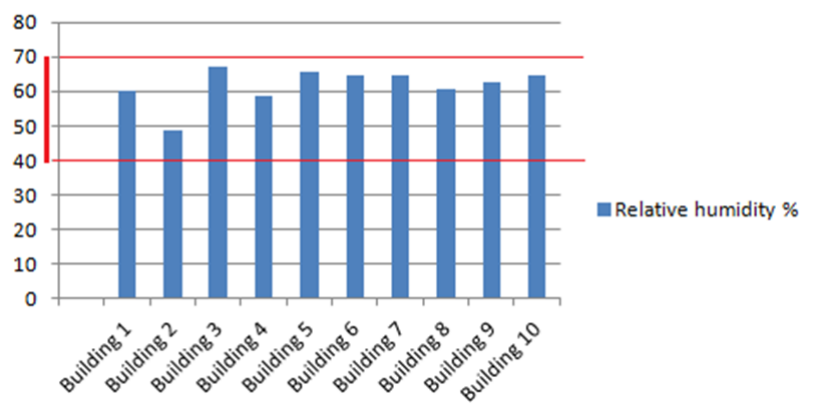

Fig. 8. Relative humidity measurement of different buildings and its corresponding ICOP standards limit.

\subsection{Formaldehyde}

Based on Figure 9, it has been shown that measurements taken for all buildings are between the acceptable ranges. However, if the ozone measurements are out of acceptable range, there might be some effect to building occupants. The major toxic effects caused by acute formaldehyde exposure via inhalation are eye, nose, and throat irritation and effects on the nasal cavity are acute effects. Other effects seen from exposure to high levels of formaldehyde in humans are coughing, wheezing, chest pains, and bronchitis.

\section{Formaldehyde ppm}

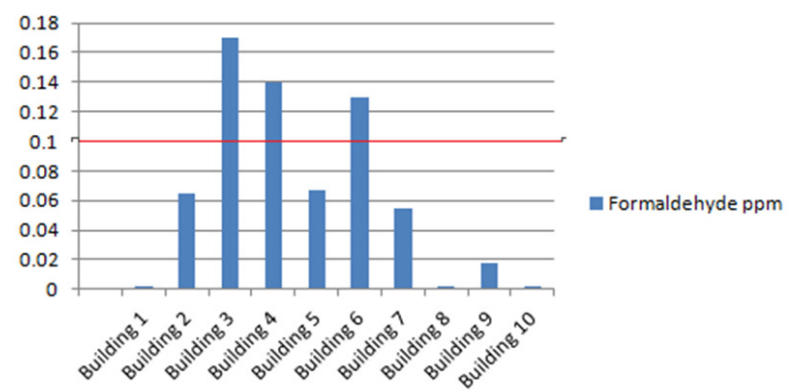

Fig. 9. . Formaldehyde measurement of different buildings and its corresponding ICOP standards limit.

\section{Conclusions}

From this monitoring of indoor air quality, it is found that a number of buildings have poor indoor air quality, thus not follow ICOP 2010. This study is important to determine the level of indoor air quality of a workplace so that improvement measures can be undertaken in the future to reduce health problems among occupants. Therefore, ongoing renovations should not use toxic materials. The renovations done should use materials that release low VOC. The smoking ban should be enforced in order to achieve the building standards of good indoor air quality. An inspection of the building and HVAC system should be run by the 
owners of the building at least every six months. The maintenance work must comply with the manufacturer's recommendations.

The authors would like to extend their indebtedness to Universiti Malaysia Pahang for the financial support under the internal research grant RDU1403120 and provision of research facility during the research undertaking.

\section{References}

1. Z. Tong, Y. Chen, A. Malkawi, G. Adamkiewicz, and J. D. Spengler, Environ. Int. 8990, 138-146 (2016).

2. H. Rohra and A. Taneja, Atmos. Environ. 129, 243-255 (2016).

3. A. A. Zorpas and A. Skouroupatis, Sustain. Cities Soc. 20, 52-60 (2016).

4. M. Ivanov, Energy Procedia 85, 295-302 (2016).

5. Z. Wang, H. Zhao, B. Lin, Y. Zhu, Q. Ouyang, and J. Yu, Build. Environ. 94, 593-605 (2015).

6. G. G. Mandayo, J. Gonzalez-Chavarri, E. Hammes, H. Newton, I. Castro-Hurtado, I. Ayerdi, H. Knapp, A. Sweetman, C. N. Hewitt, and E. Castaño, Urban Clim. 14, 475485 (2015).

7. S. A. Abdul-Wahab, S. Chin Fah En, A. Elkamel, L. Ahmadi, and K. Yetilmezsoy, Atmos. Pollut. Res. 6(5), 751-767 (2015).

8. E. Nozza, L. Capelli, L. Eusebio, M. Derudi, G. Nano, R. Del Rosso, and S. Sironi, Build. Environ. 98, 98-106 (2016).

9. A. Mendes, S. Bonassi, L. Aguiar, C. Pereira, P. Neves, S. Silva, D. Mendes, L. Guimarães, R. Moroni, and J. P. Teixeira, Urban Clim. 14, 486-501 (2015).

10. A. Hesaraki, J. A. Myhren, and S. Holmberg, Sustain. Cities Soc. 19, 165-172 (2015).

11. J. Yang, I. Nam, H. Yun, J. Kim, H.-J. Oh, D. Lee, S.-M. Jeon, S.-H. Yoo, and J.-R. Sohn, Atmos. Pollut. Res. 6(6), 1113-1122 (2015).

12. S. Langer, G. Bekö, E. Bloom, A. Widheden, and L. Ekberg, Build. Environ. 93, 92$100(2015)$.

13. T. Hu, W. Jia, R. Huang, H. Li, S. Liu, T. Ma, and Y. Zhu, Atmos. Environ. 123, 449454 (2015).

14. E. Can, Ö. Özden Üzmez, T. Döğeroğlu, and E. O. Gaga, Atmos. Pollut. Res. 6(6), 10351045 (2015).

15. J. Madureira, I. Paciência, J. Rufo, E. Ramos, H. Barros, J. P. Teixeira, and E. de Oliveira Fernandes, Atmos. Environ. 118, 145-156 (2015).

16. M. Kim, R. D. Braatz, J. T. Kim, and C. Yoo, Build. Environ. 92, 407-417 (2015).

17. D. Ciuzas, T. Prasauskas, E. Krugly, R. Sidaraviciute, A. Jurelionis, L. Seduikyte, V. Kauneliene, A. Wierzbicka, and D. Martuzevicius, Atmos. Environ. 118, 107-117 (2015). 